\title{
A SUPERAÇÃO DO ANTROPOCENTRISMO: UMA NECESSÁRIA RECONFIGURAÇÃO DA INTERFACE HOMEM-NATUREZA
}

\author{
THE ANTHROPOCENTRISM OVERCOMING: A NECESSARY \\ RECONFIGURATION OF HUMAN-NATURE INTERFACE
}

\author{
Diego Coimbra Barcelos da Silva* \\ Adir Ubaldo Rech ${ }^{* *}$
}

\begin{abstract}
Resumo: O presente artigo traça uma revisão acerca da ética ambiental e seus principais posicionamentos, trazendo uma análise crítica da influência de tais teorias na Constituição Federal de 1988, particularmente sob o prisma do direito ao meio ambiente ecologicamente equilibrado, como direito de caráter dúplice, intergeracional e fundamental. As visões antropocêntrica, sencientista, ecocêntrica e biocêntrica são apresentadas enquanto evolução do pensamento humano, revelando uma superação de paradigmas morais oriunda da histórica e imperiosa necessidade de reconfiguração da interface homem-natureza, onde a concepção da espécie humana como protagonista do mundo ao seu redor abre espaço para a ideia de que os demais elementos do ecossistema planetário possuem seu próprio valor intrínseco, em razão do papel fundamental que desempenham no meio ambiente, não mais na medida de sua utilidade para as aspirações humanas, malgrado a realidade revelar a carência de efetividade dessas novas interpretações no que diz respeito à experimentação plena do direito fundamental ao meio ambiente ecologicamente equilibrado.
\end{abstract}

Palavras-chave: Antropocentrismo; biocentrismo; ecocentrismo; ética ambiental; sencientismo.

Abstract: This article deals a review of the environmental ethics and its main positions, bringing a critical analysis about the influence of such theories in the 1988's Federal Constitution, particularly in the light of the right to an ecologically balanced environment as duplicitous, intergenerational and fundamental right. The anthropocentric, sentientist, ecocentric and biocentric views are presented as evolution of human thought, revealing an overcoming of moral paradigms, arising from the historical and imperative need for reconfiguration of the human-nature interface, where the human species, as the protagonist of the whole world, makes room for the idea that the other elements of the planetary ecosystem have their own intrinsic value, due to the key role they play in the environment, no longer to the extent of their usefulness to human aspirations, in spite of the reality revealing the lack of effectiveness of these new concepts with regard to full trial of the fundamental right to an ecologically balanced environment.

\footnotetext{
* Advogado. Mestrando em Direito (Bolsista CAPES) pela Universidade de Caxias do Sul. Pesquisador vinculado ao Núcleo de Pesquisa em sustentabilidade, da Universidade de Caxias do Sul. E-mail: coimbradv@gmail.com.

** Coordenador do Programa de Pós-Graduação em Direito da Universidade Caxias do Sul. Doutor em Direito pela Universidade Federal do Paraná (2003). E-mail: kissdaflame@gmail.com.
} 
Keywords: Anthropocentrism; biocentris; ecocentrism; environmental ethics; sentientism.

\section{INTRODUÇÃO}

O meio ambiente sadio constitui elemento indissociável da vida, melhor dizendo, é requisito indispensável da existência de qualquer forma de vida, dentre as quais, a vida humana.

Historicamente, os impactos negativos advindos da exploração dos espaços e recursos naturais por uma das espécies que compõem tal ecossistema -a espécie humana- revelam a posição de negação da subordinação que esta possui em relação ao sistema como um todo e o desprezo pelo necessário equilíbrio entre os processos destruidores e regeneradores do meio, condição fundamental para a manutenção da existência de qualquer espécie.

Entretanto, parece factível que qualquer indivíduo no planeta, independentemente de suas necessidades, motivações, cultura e formação social, reconhece o meio ambiente como dimensão indissociável da vida humana e substrato da manutenção e subsistência da vida na Terra. (LOUREIRO, 2003, p. 11)

Mesmo as sociedades que se encontram no ápice do desenvolvimento tecnológico e da mecanização do modo de vida preservam a memória de uma ancestralidade natural, que se revela na manifestação dos instintos reprodutivos e do sentimento de vulnerabilidade ante os incontroláveis fenômenos climáticos, remetendonos sempre aos perpétuos vínculos que mantemos com os ciclos físicos, químicos e biológicos do planeta.

O desgastado relacionamento da espécie humana com o mundo natural se deve em grande parte à posição do homem em relação aos demais elementos e espécies que compõe o meio ambiente, vale dizer, a concepção que a espécie humana possui do mundo ao seu redor.

Nesse sentido, Kesselring afirma que "[...] o homem está hoje localizado fora da natureza, ao menos quanto à própria autoconsciência (...), vivendo como se não fizesse parte dela, mesmo que as fronteiras entre natureza e técnica estejam abaladas" (KESSELRING, 1992, p. 19).

Essa concepção está condicionada ao ambiente cultural em que determinada parcela da sociedade está inserida e é, portanto, variável. 
A superação do antropocentrismo: uma necessária reconfiguração da interface homemnatureza

No manejo de suas capacidades exclusivas de raciocínio desenvolvido, linguagem articulada, produção de artefatos e criação de símbolos, o homem produz cultura e as sociedades delineiam representações da realidade que as cerca, esculpindo o meio que habitam segundo suas percepções.

Segundo Waldman, as sociedades humanas possuem diferentes formas de se relacionarem com o meio natural e, ainda

\footnotetext{
[...] não existe uma “ecologia humana" única. Pelo contrário, podemos notar "uma multitude de distintas ecologias, cada uma das quais, incluindo a que pertence à ciência ocidental, foi gerada por uma experiência distinta de mundo, cada uma das quais encarnando por si mesma seu próprio e único modo de compreendê-lo (WALDMAN, 2006, p. 41).
}

Com efeito, o próprio conceito de natureza está diretamente relacionado com as diferentes visões de mundo que foram manifestadas e experimentadas ao longo da história por diferentes formações sociais, oriundas da racionalidade humana.

Diante das circunstâncias atuais de exploração econômica, degradação ambiental e desigualdade social com aumento dos índices de pobreza, a realidade revela que a irracionalidade também é um produto da razão humana, sugerindo, senão, críticas, reflexões e diferentes posicionamentos acerca da relação entre o ser humano e a natureza.

Ao termos consciência dos meandros da razão humana, é possível efetivar uma prática de constante revisão de valores e posicionamentos, que nos remeta a ações ambientalmente reflexivas e coerentes.

A concretização de uma práxis ambientalmente responsável tem início na superação dos paradigmas antropocêntricos, cujo escopo nega à natureza um valor moral intrínseco. Ao constatarmos que o homem, a despeito de toda sua complexidade, é parte imanente do meio natural que o cerca, damos o primeiro passo para uma relação pacífica entre a espécie humana e a natureza.

Assim, a relação entre o homem e o meio natural em que está inserido pode ser analisada desde diferentes perspectivas, divergentes, basicamente, no que se refere ao valor moral que se atribui à natureza em cada uma delas.

Destarte, as principais correntes da ética ambiental serão analisadas a seguir, desde a concepção antropocêntrica, cujo valor moral atribuído à natureza é nulo às perspectivas que ampliam a consideração moral para além das aspirações e necessidades humanas, como o sencientismo, o biocentrismo e o ecocentrismo. 


\section{O ANTROPOCENTRISMO}

De origem greco-latina (anthropos, o homem; centricum, centrado), o vocábulo diz respeito à posição central da espécie humana em relação ao universo. Nessa concepção, os demais integrantes do ecossistema ocupam uma posição periférica, condicionada às necessidades do homem, relevando em importância à medida que se fazem úteis aos desideratos da espécie.

Filosoficamente, a concepção antropocêntrica se refere ao homem como a referência máxima e absoluta de valores num determinado sistema, tendo tal corrente ganhado ampla aceitação no mundo ocidental a partir das proposições racionalistas que pressupunham a razão como atributo exclusivo da espécie humana.

Com a evolução cientifico-tecnológica o homem se reafirma na posição de dominador do meio em que habita, modelando o meio natural para além de suas necessidades, em detrimento dos valores intrínsecos da natureza.

Nesse sentido, Gonçalves (2010) afirma que a ideia do "homem nãonatural", exterior ao meio em que vive se solidificou com a sociedade industrial, a partir do capitalismo.

Evidentemente, a coisificação das demais espécies e recursos que compõem o meio ambiente a fim de atender às exigências do desenvolvimento econômico veio a colidir com a constatação de que tais elementos são finitos ou possuem uma capacidade de regeneração muito menor que a capacidade destrutiva do homem.

Assim, o capitalismo desenfreado às expensas dos recursos naturais vislumbrou um ponto de fraqueza: A necessidade da manutenção do meio para que o progresso econômico possa coexistir.

Nesse ponto, a doutrina traz uma segunda acepção à visão antropocêntrica clássica, radical ou egocentrismo: o "antropocentrismo conservacionista" (ROCHA, 2002).

Se de um lado, ao egocentrismo importa o crescimento econômico à qualquer custo, pois este trará o benefício geral aos homens, do outro, o antropocentrismo conservacionista reconhece as limitações do meio natural e a importância de sua preservação para os fins da continuidade do desenvolvimento e da manutenção da vida humana. Todavia, ambas concepções convergem no sentido de que 
A superação do antropocentrismo: uma necessária reconfiguração da interface homemnatureza

o valor dos elementos naturais é quantificado no proveito humano que estes possam gerar.

Nesse panorama, passaram as nações a preocupar-se com o hiperdesenvolvimento, buscando formas de desenvolvimento menos agressivas ao meio natural, em que pese por razões de ordem político-econômicas.

Em 1972, a Conferência de Estocolmo, precedida de diversos movimentos populares que questionavam os padrões desenvolvimentistas, estabelece o marco inicial das preocupações em nível mundial com a qualidade ambiental. No encontro, 113 países discutiram as perspectivas, problemas e as relações entre o desenvolvimento e o meio ambiente.

$\mathrm{Na}$ esteira da necessidade da existência de um ponto de equilíbrio entre o desenvolvimento e manutenção dos recursos naturais, em 1983 surge o famigerado termo “desenvolvimento sustentável", utilizado pela primeira vez por ocasião da Comissão Mundial sobre Meio Ambiente e Desenvolvimento, da ONU, cujo trabalho resultou no relatório Brundtland.

Segundo o documento, desenvolvimento sustentável "[...] é aquele que atende às necessidades do presente sem comprometer a possibilidade de as gerações futuras atenderem a suas próprias necessidades" (COMISSÃO MUNDIAL SOBRE MEIO AMBIENTE E DESENVOLVIMENTO, 1988).

Saliente-se que o termo "necessidades" revela nitidamente a visão antropocêntrica em comento, em que pese as propostas positivas e o avanço que representa nas discussões internacionais em matéria ambiental.

Em resumo, traz ainda o relatório:

Em essência, o desenvolvimento sustentável é um processo de transformação no qual a exploração dos recursos, a direção dos investimentos, a orientação do desenvolvimento tecnológico e a mudança institucional se harmonizam e reforçam o potencial presente e futuro, a fim de atender às necessidades e aspirações humanas (Grifo nosso) (COMISSÃO MUNDIAL SOBRE MEIO AMBIENTE E DESENVOLVIMENTO, 1988).

O trecho acentua definitivamente que as preocupações ambientais se justificam enquanto necessárias às aspirações humanas, fazendo dos ecossistemas nada além de meros instrumentos a serviço do seu senhor -o homem.

Com efeito, a ética ambiental antropocêntrica é também o pano de fundo do direito ambiental pátrio. A Constituição Federal de 1988, ao contrário das precedentes, inaugura um capítulo exclusivamente dedicado ao meio ambiente, trazendo o status de 
direito fundamental ao meio ambiente equilibrado. O caput do exordial art. 225 assim dispõe:

Todos têm direito ao meio ambiente ecologicamente equilibrado, bem de uso comum do povo e essencial à sadia qualidade de vida, impondo-se ao Poder Público e à coletividade o dever de defendê-lo e preservá-lo para as presentes e futuras gerações (BRASIL, 1988).

Sublinhe-se aqui a inteligência da mais alta corte em matéria constitucional

do país, o Supremo Tribunal Federal, quando, nos dizeres do Relator, Ministro Celso de Mello, se refere ao dispositivo:

Todos têm direito ao meio ambiente ecologicamente equilibrado. Trata-se de um típico direito de terceira geração (ou de novíssima dimensão), que assiste a todo o gênero humano (RTJ 158/205-206). Incumbe, ao Estado e à própria coletividade, a especial obrigação de defender e preservar, em benefício das presentes e futuras gerações, esse direito de titularidade coletiva e de caráter transindividual (RTJ 164/158-161). O adimplemento desse encargo, que é irrenunciável, representa a garantia de que não se instaurarão, no seio da coletividade, os graves conflitos intergeneracionais marcados pelo desrespeito ao dever de solidariedade, que a todos se impõe, na proteção desse bem essencial de uso comum das pessoas em geral. (Grifo nosso) (STF, 2006).

Note-se que o texto da Lei fundamental e o posicionamento do STF revelam seguramente a visão segundo a qual o homem é o referencial valorativo de todas as demais coisas que existem no meio natural e que este deve ser preservado em razão das demandas da humanidade, como a vida, a saúde e a dignidade das pessoas.

Para Benjamin, o perfil antropocêntrico da proteção ambiental de base constitucional se traduz, de fato, na tutela da saúde pública:

Faltando uma base incontroversa de apoio na Constituição, o legislador ordinário foi buscar suporte na salvaguarda da saúde, sob o argumento de que ela não pode ser assegurada em ambiente degradado. Ou seja, degradação ambiental seria sinônimo de degradação sanitária. Uma argumentação de cunho estritamente homocêntrico [antropocêntrico], com indisfarçável conteúdo economicista e utilitarista. Naquele período, tal raciocínio vingou e serviu para dar sustentação à intervenção legislativa, recebendo, inclusive, respaldo judicial (BENJAMIN, 1999, p. 53).

Sendo o direito uma ordenação ética, criada pelos homens, cujo destinatário é o próprio homem (ou a sociedade), é natural a opção pelos moldes antropocêntricos.

Essa concepção se reforça ainda mais a partir do princípio fundamental da dignidade da pessoa humana como fundamento ético justificador do Estado Democrático de Direito.

Segundo Comparato: 
A superação do antropocentrismo: uma necessária reconfiguração da interface homemnatureza

\footnotetext{
Se o direito é uma criação humana, o seu valor deriva, justamente, daquele que o criou. $\mathrm{O}$ que significa que esse fundamento não é outro, senão o próprio homem, considerado em sua dignidade substancial da pessoa, diante da qual as especificações individuais e grupais são sempre secundárias (COMPARATO, 1998, p. 1).
}

Assim, a concepção antropocêntrica passa ao largo do reconhecimento da dignidade de todos os outros seres e elementos que compõem o ecossistema, reduzindoos a ferramentas a serviço do homem. Com efeito, o verdadeiro valor está na vida humana.

Contudo, aos homens, a vida não basta. É necessário que esta vida seja digna. Tamanha importância de uma vida digna, que o princípio da dignidade da pessoa humana se revela no verdadeiro fundamento ético justificador do Estado Democrático de Direito, princípio matriz das sociedades democráticas.

Nesse ponto está o grande paradoxo da concepção antropocêntrica: a vida com dignidade só pode perpetrar-se em um ambiente natural equilibrado, e este, por sua vez, só existe onde todos os seres e elementos do ecossistema desempenham o seu papel.

Negar o valor moral das demais espécies, reduzindo a preservação do meio ambiente à garantia da continuidade da vida humana e de seu desenvolvimento é, no mínimo, contraditório, de modo que a própria vulnerabilidade humana sugere uma revisão filosófica e prática do conceito de natureza, para além dos limites antropocêntricos, menos restrito ao ego humano e mais voltado ao universo que o cerca e do qual é parte.

\section{O SENCIENTISMO}

Em Kant, o homem é o ser racional, aquele que dá por si a sua própria lei e cuja natureza já o distingue das demais espécies, sendo ele um fim em si mesmo. Para o autor, as demais espécies integram o rol das coisas, cujo valor é meramente instrumental. (KANT, 1988)

Nesse diapasão, a moral Kantiana parte do pressuposto de que a pessoa -ser dotado de racionalidade- jamais poderá ser usada como meio, vez que digna de respeito, de valor, enquanto as coisas teriam, no máximo, um preço.

Singer (1990) cita que, em 1780, enquanto Kant afirmava a seus alunos que os animais, por não possuírem autoconsciência, não eram merecedores de direitos ou 
deveres por parte dos humanos, devendo ser vistos como meros meios para satisfazer os fins deste último, Jeremy Bentham, neste mesmo ano, “[...] fornecia uma resposta definitiva a Kant: A questão não é: Podem eles raciocinar? nem: Podem eles falar? mas: Podem eles sofrer?" (SINGER, 1990, p. 62).

O questionamento de Bentham ilustra muito bem o termo senciência que, apesar de, etimologicamente, referir-se à consciência de algo ou alguém, assume a conotação mais usual de consciência de dor ou prazer.

A senciência é o argumento central do sencientismo, também chamado de ética do bem-estar animal e é uma das vertentes da ética utilitarista, da qual Bentham é um dos principais expoentes, cuja consequência do ato é o fator a ser considerado em um dilema moral, em outras palavras, para a ética utilitarista, o melhor ato é aquele capaz de gerar a melhor consequência para o maior número de envolvidos, independentemente de quem sejam e, a melhor consequência é aquela em que se verifica a maximização do bem-estar, da felicidade e do prazer. Evidentemente, as ações que gerem minimização da dor e da tristeza para o maior número de envolvidos seguem a mesma lógica utilitarista.

A ética ambiental sencientista rompe o paradigma antropocêntrico quando atribui valor moral à comunidade dos seres sencientes, onde incluem-se aqueles que possuem sensibilidade à dor e prazer.

Assim, a capacidade que um ser vivo possui de experimentar as sensações dolorosas e prazerosas é a medida de seu pertencimento ao grupo dos seres aos quais se atribui valor moral intrínseco, na perspectiva sencientista.

Entretanto, é justamente no critério de ingresso de um dado ser vivo nesta comunidade que se encontram os maiores problemas postos à ética do bem-estar animal.

A experimentação cotidiana nos mostra que alguns animais podem sentir dor e prazer. Essa constatação é óbvia e instantânea quando exteriorizada por um animal que emite altos ruídos, quando ferido, por exemplo. Na maioria dos casos, vertebrados, animais cujas reações à dor são semelhantes às nossas. Tarefa mais árdua é encampar na mesma concepção seres cujas reações são imperceptíveis ou mesmo não se exteriorizam, contudo não afastam a capacidade de sentir.

Essa dificuldade sugere que os valores morais podem ser atribuídos através de filtros antropocêntricos, consoante critérios baseados na experimentação humana do mundo, na forma de sentir ou exteriorizar a dor ou o prazer. Tal crítica aponta traços da 
A superação do antropocentrismo: uma necessária reconfiguração da interface homemnatureza

influência antropocêntrica mesmo em uma concepção que busca a superação desses paradigmas, ampliando a moralidade para além dos seres humanos.

Não obstante, satisfeitos os pressupostos de definição dos seres dignos de valor moral, isto é, aqueles que apresentam senciência, ainda que calcados na fisiologia, o argumento sencientista estabelece o respeito e proteção de toda comunidade de seres capazes de sentir dor e prazer, de modo que as ações humanas não somente evitem o sofrimento mas potencializem o bem-estar das demais espécies sencientes, vez que o homem é o único ser capaz de prever consequências e arbitrar seus atos, na esteira de seu ínsito atributo - a razão.

\section{O ECOCENTRISMO}

O ecocentrismo ou fisiocentrismo foi concebido a partir dos estudos de Aldo Leopold (1989) e de Arne Naess (1973), e se refere à postura ética em que todas as formas de vida não-humanas possuem valor próprio e, a natureza, em todas as suas nuances, antecede o homem, que dela é parte integrante.

Tal concepção representa o reconhecimento de que a espécie humana é apenas uma entre tantas outras e acentua a mútua relação de dependência entre todos os entes da natureza, sejam vivos ou não, sob uma clara influência da ecologia clássica, cujo principal enfoque são as relações mútuas entres os diversos organismos, sua adaptação ao meio e sua transformação através da luta pela vida. (HAECKEL, 1866)

Trata-se, em verdade, de uma gama de correntes teóricas da ética ambiental cujo ponto de intersecção é a dilatação da atribuição de valor moral à todas as espécies e elementos do ecossistema, onde as preocupações se voltam para os interesses da comunidade biótica como um todo, através da manutenção da regular interação entre os seres e recursos naturais.

Note-se que, segundo a visão ecocêntrica, a medida do valor moral de qualquer ser ou elemento individual é a sua relação com a comunidade, vale dizer, a coletividade sobrepõe a individualidade.

Nesse sentido, Farias destaca que "[...] o indivíduo se dilui no todo, por isso o ecocentrismo é um tipo de ética ambiental holística, o valor está no todo e as partes valem enquanto estão integradas (...) nesse todo" (FARIAS, 2014, p. 611).

Com efeito, o paradigma ecocêntrico começa a ganhar força através dos referenciais trazidos pela ecologia, cujos pressupostos trazem a compreensão de que não 
há relação hierárquica entre os seres naturais, tampouco se apartam desses os homens. É o entendimento de que o homem é parte integrante da "teia da vida". (CAPRA, 1996)

Em "Ética da Terra", do original "The Land Ethics", Leopold (1989) define a matriz do ecocentrismo: “[...] Uma coisa está certa quando tende a preservar a integridade, a estabilidade e a beleza da comunidade biótica; está errada quando tem a tendência inversa" (LEOPOLD, 1989).

Entretanto, é na observação de que a preservação de tais requisitos, importantes à biodiversidade, passa pela redução do desequilíbrio ecológico, que se fundamentam as principais críticas às correntes ecocêntricas.

Um desequilíbrio ecológico pode ser definido como uma redução ou aumento populacional de determinada espécie, tendo como consequência direta a competição por alimento e locais habitáveis, o que pode se dar em razão da ação humana ou da ação da natureza.

Assim, o ecocentrismo sugere que a manutenção do necessário equilíbrio deve abarcar o controle populacional, não implicando qualquer distinção entre espécies, uma vez que todas são merecedoras de valor, na razão do papel que desempenham no ecossistema.

Nesse ponto, as discussões acerca dos critérios e formas de redução ou aumento de espécies ressoam catastróficas, haja vista a negação de qualquer valor individual em prol de um equilíbrio que poderá se valer da redução forçada de determinada espécie - "ecofascismo", diriam as mais contundentes críticas.

Contudo, se o controle populacional com vistas ao equilíbrio ecológico e a mitigação do valor individual são motivos de calorosas discussões afetas ao ecocentrismo, é razoável crer que estender o valor moral à comunidade biótica é um passo importante na superação do antropocentrismo, ainda que precisemos encontrar um ponto de equilíbrio que garanta a promoção da vida em todas as suas formas e a manutenção de suas necessárias relações de mútua dependência.

\section{O BIOCENTRISMO}

O biocentrismo, teoria desenvolvida por Paul W. Taylor (1987), também ultrapassa a barreira da restrição moral aos seres humanos, ampliando-o a todas as entidades naturais vivas. 
A superação do antropocentrismo: uma necessária reconfiguração da interface homemnatureza

A luta pela vida, traduzida nas transformações e adaptações das espécies, como forma de manutenção da existência, é o fundamento para a valoração moral de todos os seres, de modo que o valor da vida, em si e por si mesma, não prescinde de qualquer finalidade humana.

Taylor delineia os parâmetros da ética ambiental biocêntrica, estabelecendo ainda seu rompimento com o ecocentrismo: "A nossa concepção de cada organismo como um centro teleológico de vida é tanto o reconhecimento da realidade da sua existência como da sua individualidade única, que persegue o seu próprio bem à sua maneira" (TAYLOR, 1987, p. 128).

Com efeito, na contramão do que muitos consideram como uma vertente do ecocentrismo, a visão biocêntrica funda-se no valor individual de cada vida humana ou não humana, em detrimento da visão holística de um ecossistema global, bem como nega o harmônico equilíbrio entre as espécies.

Embora os organismos vivos façam parte de uma comunidade global de vida na Terra - a biosfera-, o biocentrismo ressalta a impossibilidade da promoção do bem de toda a comunidade biótica sem que, antes, se atenda ao bem próprio de cada organismo.

Nesse passo, é razoável prever que nessa extensa comunidade de seres com diferentes interesses, todos dignos de tutela moral, a satisfação da necessidade de um dado ser poderá interferir negativamente na satisfação das demais, gerando conflitos. Tais conflitos rompem com a visão holística ecocêntrica de uma comunidade biótica que tende ao equilíbrio natural.

Taylor admite um nível mínimo de equilíbrio, mas indica que a necessidade de um novo modelo ético para as relações entre o homem e o ambiente deve pressupor o conflito de interesses e não a harmonia.

A solução de inevitáveis conflitos se dará em função da importância dos interesses e não dos seres envolvidos, vez que não há qualquer relação hierárquica entre eles, entretanto, compete aos agentes morais racionais a elucidação dos conflitos entre os sujeitos, sem, contudo, levar-se em conta apenas os interesses humanos.

Essa concepção considera que enquanto os elementos do meio natural seguem seu curso inescapável segundo as leis da natureza, o homem possui deveres em razão de sua liberdade para escolher as ações que menos impacto causem às demais espécies, melhor dizendo, evitar o conflito de interesses entre a sua espécie e as demais ou o próprio meio como um todo. Assim, às demais espécies, o biocentrismo atribui o 
direito de não terem sua vida ou seu curso evolutivo turbado pela ação humana e, tal direito pressupõe qualquer consciência de valor.

Nesse sentido Taylor (1987, p. 158) esclarece que:

[...] enquanto agentes morais, nos vemos sob a exigência ética de conceder igual consideração ao bem de todas as entidades com um bem próprio, humanas e não-humanas. Quando o bem de um conflita com o de outro, reconhecemos dever ser imparciais em nossa abordagem inicial, para encontrar um modo justo de resolver o conflito. Dado que todos são vistos como tendo o mesmo valor inerente, a atitude de respeito é igualmente devida a cada um (TAYLOR, 1987, p. 158).

Destarte, as ideias biocêntricas são absolutamente opostas à consideração de superioridade do ser humano. O núcleo moral é a reverência à vida, em todas as suas formas, revelada no respeito à individualidade de cada organismo.

Todavia, o biocentrismo enfrenta sérias críticas cujos fundamentos dizem respeito à sua inviabilidade, limitação e individualismo:

Inviável, por constituir-se em uma visão demasiadamente romântica das relações entre os seres na natureza, implicando, em um primeiro aspecto, na ausência da interferência humana, o que está à margem da utopia, pois o homem é um ser cujas necessidades ultrapassam a mera sobrevivência e; em um segundo aspecto, admitindose a interferência humana, segundo suas necessidades, mediante critérios préestabelecidos de resolução de conflitos, os quais serão aplicados pelo próprio homem -o que sugere um favorecimento do ser moral racional.

Limitado, por reconhecer valor intrínseco apenas aos seres vivos, biologicamente organizados, com capacidade de funcionamento e ritmos próprios de crescimento e desenvolvimento, o que, obviamente, não se estende a tantos outros elementos do ecossistema, cuja importância transcende a sua existência, mas se afigura no papel que desempenha no todo.

Individualista, por furtar o valor moral dos ecossistemas e da comunidade biótica, olvidando-se das mútuas relações de dependência existentes entre os seres vivos humanos e não humanos e os demais elementos da biota.

Em que pese as duras críticas, a corrente biocêntrica caminha positivamente na direção oposta ao antropocentrismo, representando uma renovação do pensamento humano quanto a sua relação com o mundo que o cerca.

\section{CONCLUSÃO}


A superação do antropocentrismo: uma necessária reconfiguração da interface homemnatureza

Com o desenvolvimento da ciência no conhecimento do ecossistema planetário, notadamente acerca do fenômeno da vida, suas nuances e significados, bem como do impacto que a intervenção do homem gera no ambiente e suas consequências negativas à própria espécie humana, urge a necessidade de uma remodelação de paradigmas, através do reposicionamento do homem diante do meio que o cerca.

Com efeito, a figura do homem soberano, senhor de todas as outras coisas, cujo valor se atribui segundo as necessidades e ambições da humanidade vem, há muito tempo, dando sinais de fraqueza ante a constatação de que o equilíbrio do meio ambiente é condição fundamental para a vida e o desenvolvimento de qualquer espécie, inclusive a humana.

A visão antropocêntrica do mundo exterior vai dando espaço às posturas éticas que reconhecem o valor intrínseco e inalienável do mundo que nos rodeia e que nos precede, já que a vida humana é uma realidade muito recente, se comparada à evolução do planeta e de tantas outras espécies.

Se considerarmos que o homem é o principal beneficiário de um meio ambiente equilibrado e que, para tanto, protegemos a natureza em prol da vida humana, veremos que a razão de tal proteção se deve exclusivamente ao fato de que o homem é o único responsável pelos desarranjos ambientais. De outro modo, não haveria qualquer sentido falar em proteção ambiental.

Portanto, não há razão em negar às demais espécies e recursos que compõem a natureza o seu valor moral pelo que são, pelas funções que desenvolvem cada um no ecossistema, no equilíbrio de que tanto necessita o homem para sua própria sobrevivência.

Contudo, muito ainda há que se fazer. A ética antropocêntrica ainda está arraigada no seio das sociedades e as nações pouco têm feito, em termos práticos, acerca do controle de riscos globais ambientais, simplesmente porque o desenvolvimento de um país é medido em escala econômica e, este, grande parte das vezes relega à proteção ambiental uma posição subsidiária, quando não a de absoluto obstáculo aos seus interesses.

\section{REFERÊNCIAS}


BENJAMIN, Antônio Herman de Vasconcellos. Introdução ao Direito Ambiental Brasileiro. Revista de Direito Ambiental, n.14. São Paulo: RT, 1999.

BRASIL. Constituição da República Federativa do Brasil de 1988. Disponível em: <http://www.planalto.gov.br/ccivil_03/constituicao/constituicao.htm>. Acesso em: 10 nov. 2017.

CAPRA, Fritjof. A teia da vida: Uma nova compreensão científica dos sistemas vivos. São Paulo: Cultrix, 1996.

COMISSÃO MUNDIAL SOBRE MEIO AMBIENTE E DESENVOLVIMENTO. Nosso futuro comum (Relatório Brundtland). Rio de Janeiro: FGV, 1988.

COMPARATO, Fábio Konder. Fundamentos dos direitos humanos. São Paulo: LTr, 1998.

DIAS, Edna Cardoso. Os animais como sujeitos de direitos. Revista Brasileira de Direito Animal, vol. I, n. I. Salvador: Instituto de Abolicionismo Animal, 2006.

FARIAS, André Brayner de. Ética para o meio ambiente. In: TORRES, João Carlos Brum. Manual de ética: questões de ética teórica e aplicada. Petrópolis: Vozes, 2014.

GONÇALVES, Carlos Walter Porto. Os (des)caminhos do meio ambiente. 2 ed. São Paulo: Contexto, 2010.

HAECKEL, Ernst. Generelle Morphologie der Organismen. Berlin: G. Reimer, 1866.

KANT, Immanuel. Crítica da razão pura. 3. ed. São Paulo: Nova Cultural, 1988.

LEOPOLD, Aldo. A Sand County Almanac, and Sketches Here and There. New York: Oxford University Press, 1989.

WALDMAN, Maurício. Meio ambiente \& antropologia. São Paulo: Editora Senac São Paulo, 2006.

NAESS, Arne. The Shallow and the Deep: Long-Range Ecology Movement: A Summary. Inquiry: An Interdisciplinary Journal of Philosophy and the Social Sciences, $\mathrm{n}^{\circ}$ 16: 95-100, 1973.

RIBEIRO JÚNIOR, J. A formação pedagógica do professor de Direito: conteúdos e alternativas metodológicas para a qualidade do ensino do Direito. 2.ed. Campinas: Papirus, 2003.

ROCHA, Julio Cesar de Sá da. Direito ambiental do trabalho: mudança de paradigma na tutela jurídica à saúde do trabalhador. São Paulo: LTr, 2002.

SINGER, Peter. Animal liberation. 2. ed. New York: Random House, 1990.

STF, Ação Direita de Inconstitucionalidade 3540 - MC, Relator Ministro Celso de Mello, Tribunal Pleno, julgado em 01/09/2005, DJ 03-02-2006. 
A superação do antropocentrismo: uma necessária reconfiguração da interface homemnatureza

TAYLOR, Paul W. Respect for Nature: a theory of environmental ethics. 2. impress with corrections. New Jersey, Princeton: Princeton University Press, 1987.

Artigo recebido em 01 de outubro de 2016 e aceito em 25 de novembro de 2017 